\title{
Bathymetry and Selected Perspective Views of Crater Lake, Oregon
}

By James V. Gardner, Peter Dartnell, Laurent Hellequin, and Charles R. Bacon, U.S. Geological Survey; Larry A. Mayer, University of New Hampshire; Mark W. Buktenica, National Park Service; and J. Christopher Stone, U.S. Geological Survey

Water-Resources Investigations Report 01-4046

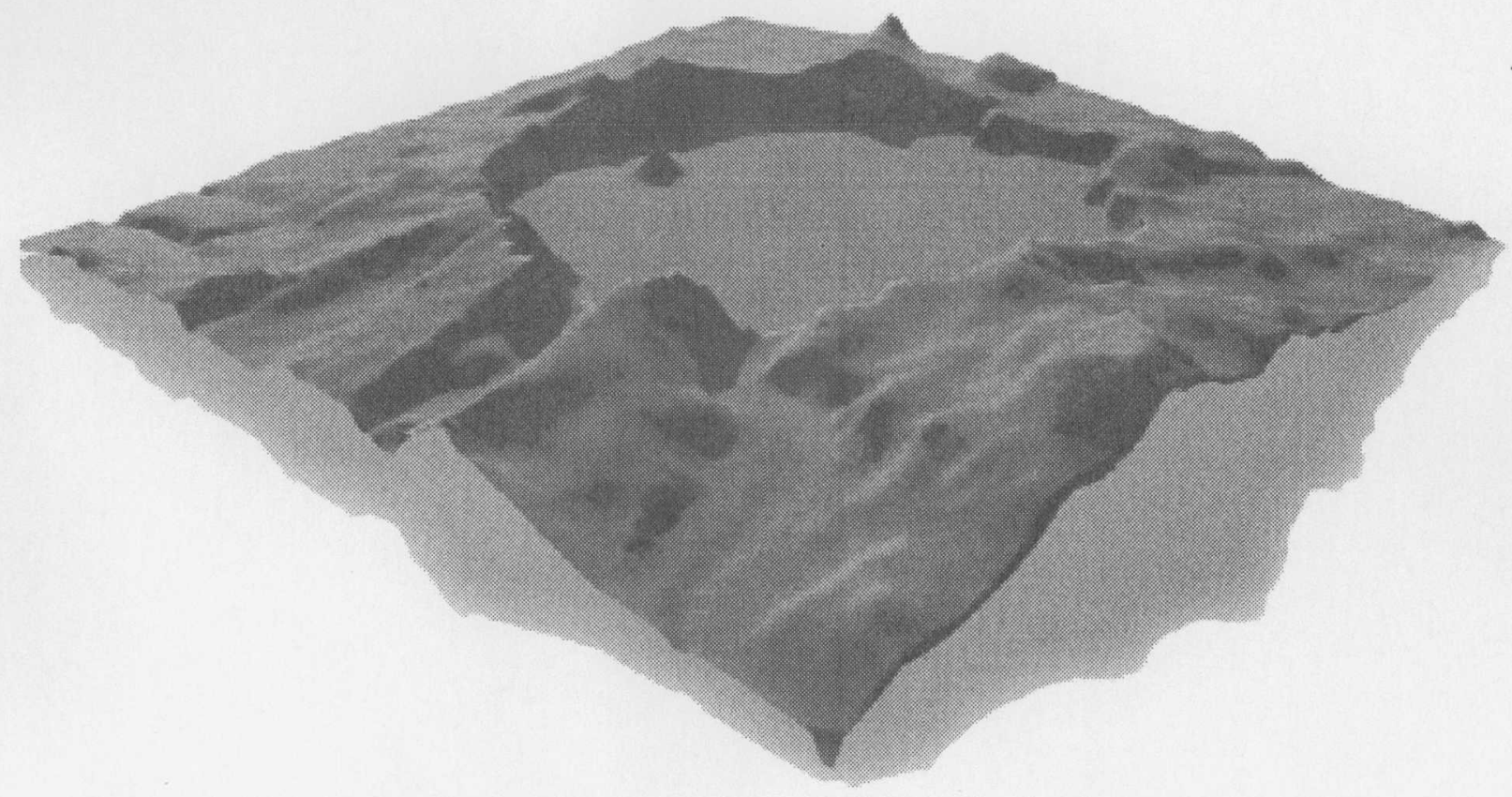

U.S. Department of the Interior

U.S. Geological Survey 